\title{
Efficient differentiation into skin cells of bone marrow cells recovered in a pellet after density gradient fractionation
}

\author{
REINHOLD J. MEDINA, KEN KATAOKA, MASAHIRO MIYAZAKI and NAM-HO HUH \\ Department of Cell Biology, Okayama University Graduate School of Medicine, \\ Dentistry, and Pharmaceutical Sciences, Okayama 700-8558, Japan
}

Received September 27, 2005; Accepted November 11, 2005

\begin{abstract}
We had previously demonstrated the participation of whole bone marrow cells from adult mice in the reconstitution of skin, including the epidermis and hair follicles. To get an insight into cell populations that give rise to the epithelial components of the reconstituted skin, we fractionated bone marrow cells derived from green fluorescent proteintransgenic mice by density gradient. Unexpectedly, we found that a substantial amount of mononucleated cells ( 30\%) was recovered in the pellet fraction and that the cells in the pellet fraction preferentially differentiated into epithelial components of skin, rather than the cells in the mononuclear cell fraction. The pellet fraction contained more CD45-negative (thus uncommitted to the hematopoietic cell lineage) cells than the mononuclear cell fraction. These results indicate that density gradient fractionation results in significant loss of specific progenitor cells into the usually discarded pellet fraction.
\end{abstract}

\section{Introduction}

Recent studies have revealed that bone marrow cells possess potency to differentiate into a broad variety of non-hematopoietic cells, including bone, cartilage (1), skeletal muscle, liver, lung (2), heart (3), brain $(4,5)$, and skin (6). As progenitors of such diverse cell types, a number of different cell populations have been indicated including hematopoietic stem cells (HSC), mesenchymal stem cells (MSC), multipotent adult progenitor cells (MAPC) and side population stem cells (SP). Furthermore, the possibility has been suggested that bone marrow harbors a variety of non-hematopoietic tissuespecific stem cells (7), such as neural stem cells, muscle stem cells and hepatic progenitors $(8,9)$. Purified adult HSC could differentiate in vivo into various cell types including hepato-

Correspondence to: Dr Nam-Ho Huh, Department of Cell Biology, Okayama University Graduate School of Medicine, Dentistry, and Pharmaceutical Sciences, 2-5-1 Shikata-cho, Okayama 700-8558, Japan

E-mail:namu@md.okayama-u.ac.jp

Key words: density gradient, multipotency, stem cells, cell transplantation, bone marrow cytes (10) and epidermal cells (6). MSC that are characterized by their adhering property to plastic substrates were shown to differentiate, not only into mesenchymal tissue such as bone, cartilage, fat, tendon and muscle (11), but also into neuronal cells (12). Verfaillie's group has isolated a rapidly growing cell population from human and rodent bone marrow, named MAPC, which has the potential for multi-lineage differentiation $(13,14)$. SP defined by their ability to rapidly expel a DNA binding dye, Hoechst 33342, can function as HSC $(15,16)$ and also contribute to bone (17) and liver (18) regeneration. Although the identity and mutual relationships of these four populations are not clearly defined, bone marrow-derived cells are considered to be the richest and most promising source for potential cell- and gene-therapies against various human diseases (19).

In almost all of the studies characterizing bone marrowderived stem cells and even in those using 'whole' bone marrow cells, the first step is isolation of mononuclear cells by density gradient centrifugation. A discrete layer of mononuclear cells is collected and other fractions, including the pellet with the bulk of erythrocytes, are usually discarded (20). As density gradient fractionation of bone marrow cells has been widely used for many years, the procedure is fully standardized $(21,22)$.

We previously showed that unfractionated bone marrow cells from green fluorescent protein (GFP)-transgenic mice could differentiate into skin cells when transplanted in a mixture of embryonic epidermal and dermal cells onto skin defects made on the back of nude mice (23). The localization and morphology of GFP-positive cells and the results of immunohistochemistry and specific staining confirmed that the cells had differentiated into epidermal keratinocytes, sebaceous gland cells, follicular epithelial cells, dendritic cells and endothelial cells. As the first step to define the cells giving rise to skin cells, we transplanted mononuclear cells (MNC) prepared using conventional density gradient fractionation. Unexpectedly, MNC differentiated mainly into mesenchymal cell components and hardly into epithelial cells comprising hair follicles and sebaceous glands. We provide evidence that the pellet fraction obtained after conventional density gradient fractionation of mouse bone marrow cells contains a substantial amount of nucleated cells. The cells were mostly not committed to hematopoietic cells and preferentially differentiated into epithelial cells of hair follicles and sebaceous glands. 


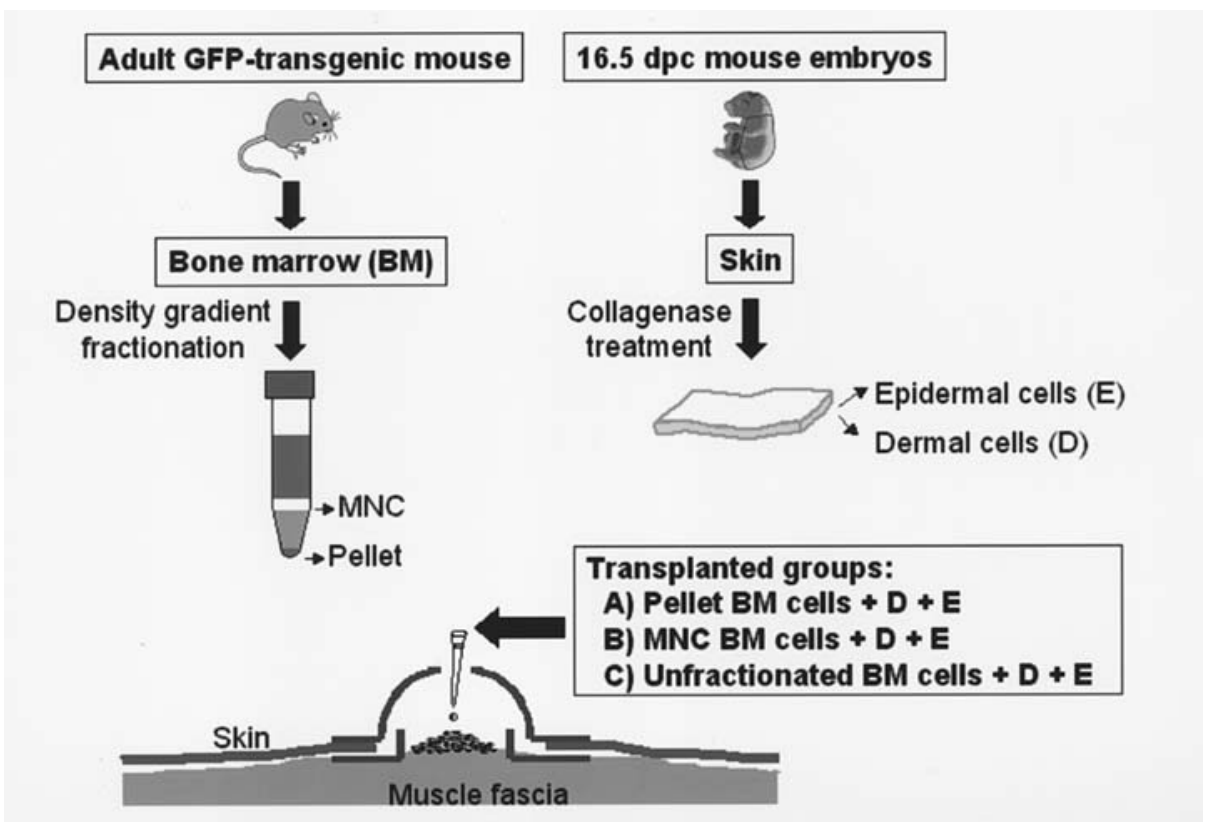

Figure 1. Skin reconstitution assay using a silicon chamber. Bone marrow cells from adult GFP-transgenic mice were fractionated by density gradient centrifugation, mixed with embryonic mouse skin cells, and transplanted into skin defects created on the backs of nude mice. MNC, mononuclear cells.

\section{Materials and methods}

Mice. Bone marrow cells were prepared from GFP-transgenic mice provided by Dr Masaru Okabe (Osaka University) at the age of 6-8 weeks. The mice ubiquitously express GFP under the control of the CAG promoter composed of the cytomegalovirus enhancer, a fragment of the chicken B-actin promoter and rabbit $\beta$-globin exons (13). We prepared epidermal and dermal cells from 16.5 days post-coitus (dpc) embryos of ICR mice (Nippon SLC, Hamamatsu, Japan). Recipient mice were BALB/c nude mice purchased from Nihon Charles River (Yokohama, Japan). Bone marrow cells for flow cytometric analysis were obtained from 6-week-old C57Bl/6 mice (Nippon SLC).

Preparation of skin cells. Mouse embryonic skin cells were prepared as previously reported (23). Briefly, dorsal skin was cut from 16.5 dpc ICR mouse embryos (30-40 embryos for one single transplantation experiment) and incubated in $0.05 \%$ collagenase (Wako, Osaka, Japan) in MCDB 153 medium (Sigma) without growth factors overnight at $4^{\circ} \mathrm{C}$. The epidermis was separated from the dermis using forceps under a dissecting microscope, and a cell suspension was obtained by gentle pipetting and filtration with a \#150 mesh (Ikemoto, Tokyo, Japan).

Isolation, fractionation, and analysis of bone marrow cells. Femurs and tibias carefully dissected from a GFP-transgenic mouse were used for transplantation. Both ends of each bone were cut and marrow cells were thoroughly washed, avoiding contamination with cells outside the bones. The cells were suspended in $8 \mathrm{ml} \mathrm{Hank's} \mathrm{balanced} \mathrm{salt} \mathrm{solution} \mathrm{(HBSS),}$ gently overlaid onto $3 \mathrm{ml}$ of Histopaque 1083 (Sigma), and centrifuged at $400 \mathrm{x}$ g for $30 \mathrm{~min}$. Each fraction (Fig. 2) was carefully taken and the cells were washed three times in
HBSS before counting. Flow cytometric analyses of size, granularity and GFP expression were performed using a cytometer type FACScalibur (BD Biosciences, San Diego, CA). For the analysis of marker proteins, bone marrow cells were first incubated with CD16/CD32 (eBioscience, San Diego, CA) to block non-specific staining of the Fc receptor for $20 \mathrm{~min}$ at $4^{\circ} \mathrm{C}$. Direct immunolabelling was performed with fluorescein isothiocyanate (FITC) or phycoerythrin (PE)conjugated monoclonal antibodies for $45 \mathrm{~min}$ at $4{ }^{\circ} \mathrm{C}$. The antibodies used were CD45-FITC, CD90.1-FITC, CD117-PE (eBioscience), CD29-FITC, $\gamma \delta$ T-cell receptor-PE (BD Biosciences), CD34-PE (Caltag, Burlingame, CA), CD49fFITC, and CD200-PE (Serotec, Oxford, UK). Immediately after washing, the cells were analyzed using FACScalibur (BD Biosciences). Cells incubated without the first antibody or with immunoglobulin of the same isotype with the respective antibody were used as negative controls.

Transplantation. The embryonic skin cell mixture was composed of $5 \times 10^{6}$ each of epidermal and dermal cells. GFP-positive bone marrow cells, either freshly isolated or after fractionation, were added at $0.5-1 \times 10^{7}$ to the skin cell mixture. Transplantation was performed as previously reported $(23,24)$. Briefly, a back skin area $(\sim 1 \mathrm{~cm}$ in diameter $)$ of nude mice was excised down to the fascia under anesthesia with $0.35 \mathrm{ml}$ of Nembutal (Abott Laboratories, North Chicago, IL), and a lower silicon chamber (Renner, Darmstadt, Germany) was implanted. The cell slurry was applied to the center of the skin defect and covered by an upper silicon chamber (Fig. 1). The chambers were removed one week after the transplantation.

Sampling, processing, and analysis of reconstituted skin tissue. Three weeks after transplantation, regenerated skin tissue was removed and fixed in $4 \%$ paraformaldehyde in PBS, followed by embedding in Technovit 8100 (Heraeus 

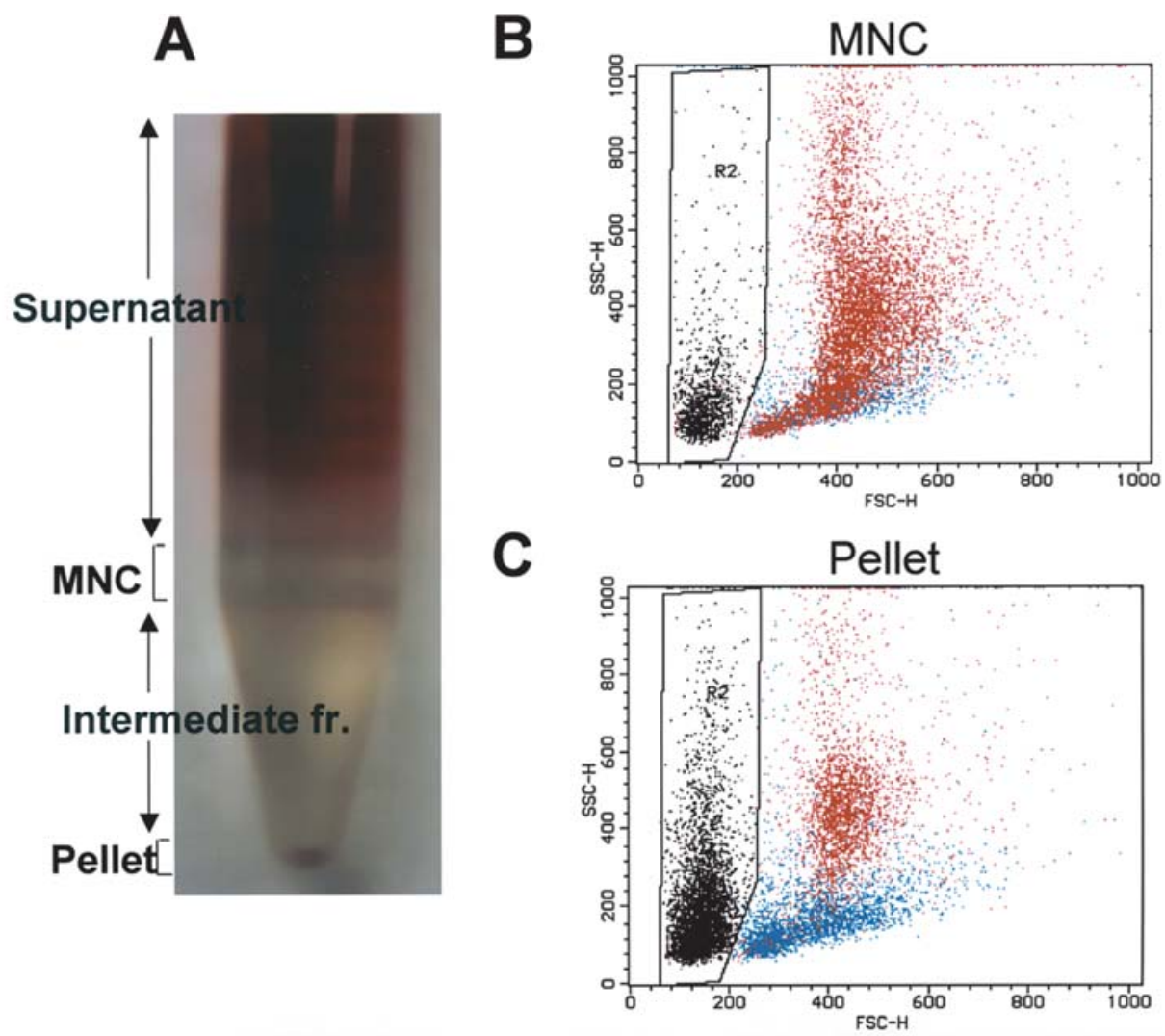

Figure 2. Density gradient fractionation of adult mouse bone marrow cells. (A) Density gradient fractionation divides the bone marrow cells into four fractions. Most of the nucleated cells were recovered in the MNC fraction (low density) and pellet fraction (high density). (B and C) Flow cytometric analysis of MNC and pellet fractions. The abscissa and ordinate are forward scatter and side scatter, respectively. GFP-positive cells (viable nucleated cells) are indicated in red. GFP-negative large (viable nucleated cells) and small cells (erythrocytes and dead cells) are indicated in blue and black, respectively.

Kulzer, Wehrhein, Germany). For each sample, at least 20 sections of $5 \mu \mathrm{m}$ in thickness were prepared and observed under a fluorescent microscope (Olympus DP70, Tokyo, Japan). After taking pictures, GFP-positive cells were counted and classified on the basis of their characteristic morphology and location. Possible differences among different experimental groups were assessed by Mann-Whitney U statistical analysis.

Immunohistochemistry and specific staining. Technovit sections (5 $\mu \mathrm{m}$ thick) were stained with rabbit polyclonal antiPan-Cytokeratin antibody (H-240; Santa Cruz Biotechnology) for identifying epithelial cells and with anti-human von Willebrand factor antibody (Dako Cytomation, Copenhagen, Denmark) for identifying endothelial cells. Positive signals were visualized using Envision+ (Dako Cytomation) and AEC solution (Nichirei, Tokyo, Japan). Staining for lipids was performed by pretreating tissue sections twice with $60 \%$ isopropyl alcohol for $5 \mathrm{~min}$ and then staining with $0.18 \%$ Oil Red O (Wako, Tokyo, Japan) in 60\% isopropyl alcohol for $7 \mathrm{~min}$.

\section{Results}

Fractionation of bone marrow cells. In our previous study, we showed that unfractionated bone marrow cells from an adult mouse participate in skin reconstitution when transplanted with embryonic skin cells (23). The bone marrow cells differentiated into diverse types of skin cells, including epidermal keratinocytes, hair follicle cells, and sebaceous gland cells. To characterize the progenitor cells further, we transplanted the MNC fraction prepared by density gradient centrifugation using Histopaque 1083 (Fig. 2A). Unexpectedly, however, we rarely detected GFP-positive cells in hair follicles and epidermis. This seems contradictory to the prevailing notion that practically all nucleated cells of bone marrow can be recovered in the MNC fraction.

When we fractionated adult mouse bone marrow cells by density gradient centrifugation using Histopaque 1083, 0\%, $62 \%\left(2.3 \pm 0.9 \times 10^{7}\right.$ cells per two mice), $7 \%\left(2.5 \pm 2.0 \times 10^{6}\right.$ cells per two mice) and $31 \%\left(1.2 \pm 0.3 \times 10^{7}\right.$ cells per two mice $)$ of nucleated cells were recovered in the supernatant, MNC, intermediate and pellet fractions, respectively (Fig. 2A). Nucleated cells comprised $68 \%$ and $41 \%$ of the MNC and pellet fractions, respectively, while erythrocytes were partially lysed during the fractionation procedure. Cell populations in the MNC and pellet fractions showed different patterns in dot plotting with respect to side/forward scattering and GFP expression after FACS analysis (Fig. 2B and C). Among the nucleated cells (i.e., large cells), $91 \%$ and $58 \%$ were positive for GFP in the MNC and pellet fractions, respectively. These fractionation profiles were essentially the same as those obtained by density gradient centrifugation using Ficoll, Percoll or Histopaque 1077 (data not shown).

Identification of bone marrow-derived cells in the reconstituted skin. Different cell types derived from GFP-positive bone marrow cells were determined by the location and shape of 

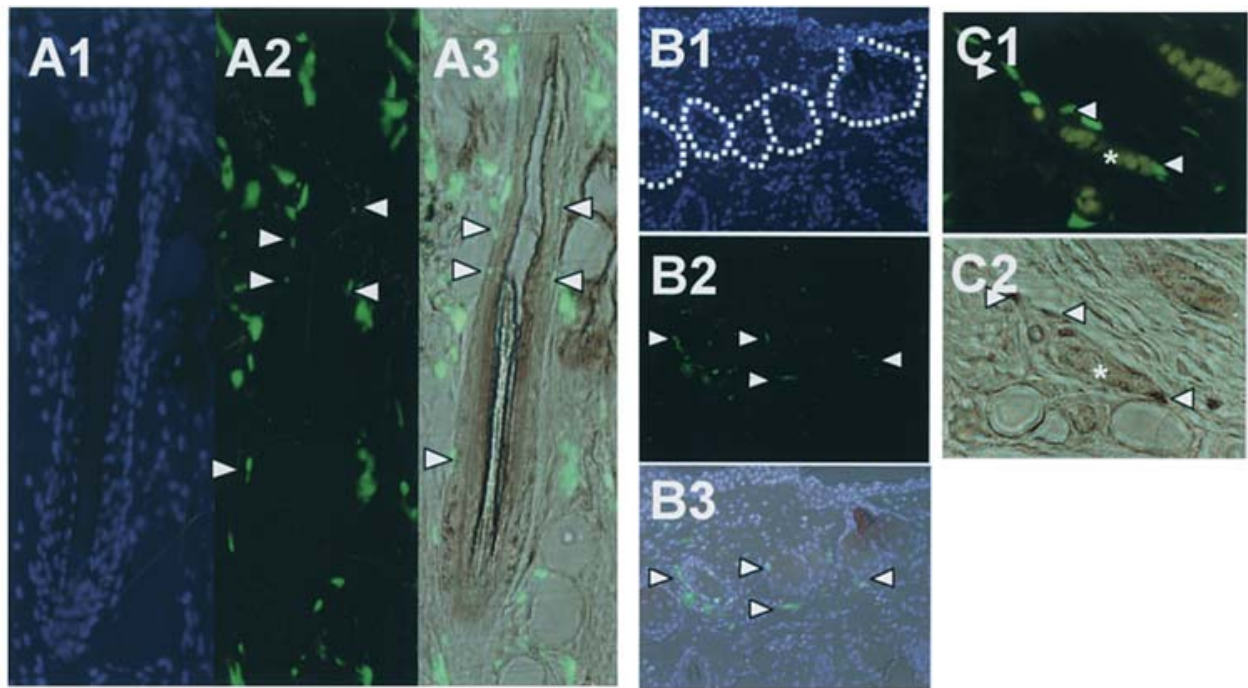

Figure 3. Immunohistochemistry showing multipotent differentiation capacity of bone marrow cells. (A) Cells composing hair follicles formed by transplantation of the pellet fraction. Co-localization of GFP signal (A2) and cytokeratin expression (A3). Nuclei were stained with DAPI (A2). (B) Peri-sebaceous gland cells after transplantation of the pellet fraction. (B1) DAPI staining with dotted lines indicating the sebaceous glands; (B2) GFP signal present in the outer layer of sebaceous glands; (B3) a merged image of GFP and Oil Red O staining. (C) Endothelial cells after transplantation of the MNC fraction. GFP signal (C1) was co-localized with von Willebrand factor (C2) as indicated by arrowheads. Erythrocytes were observed in the vessel lumen $(*)$.

A

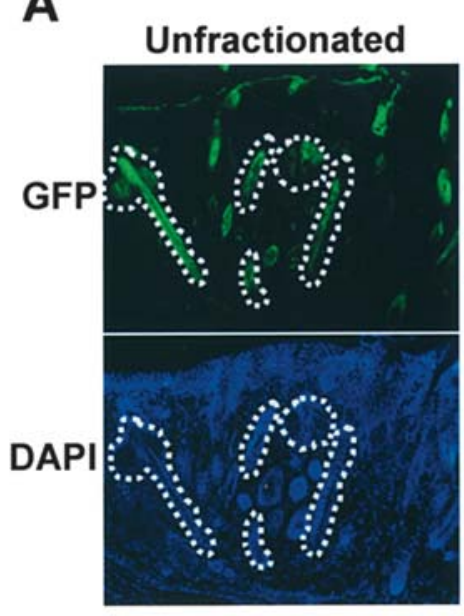

B
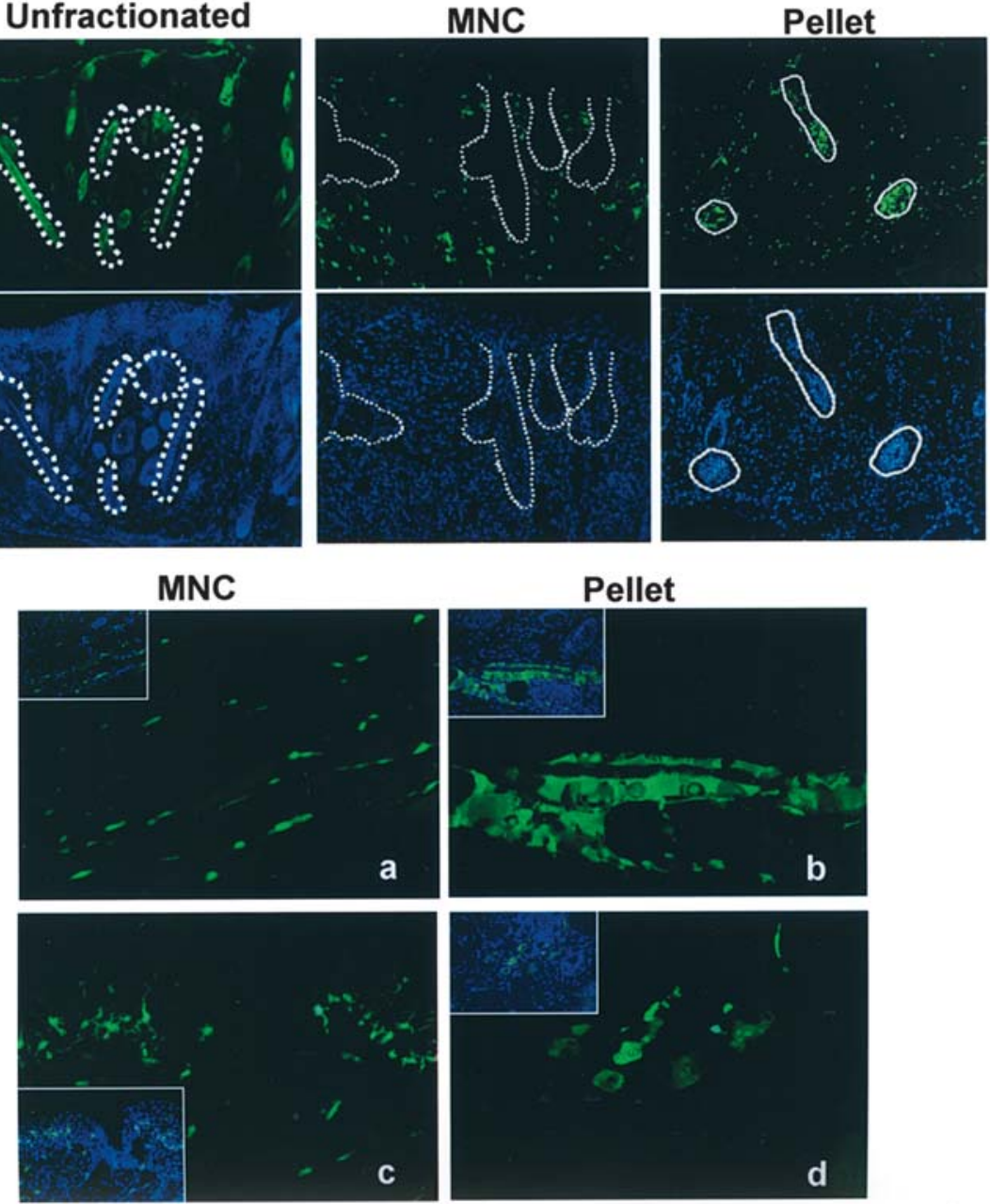

Figure 4. Distinct preference in differentiation of whole bone marrow cells, MNC and pellet cells into skin cells. Whole bone marrow cells and pellet cells frequently differentiated into hair follicle cells and sebaceous gland cells (A and B), whereas MNC preferentially differentiated into endothelial cells and dendritic cells but rarely into hair follicle cells. Insets in B show merged images of GFP signal and DAPI staining. Dotted lines in A indicate hair follicles. (B-a) Endothelial cells; (B-b) hair follicle cells; (B-c) dendritic cells; (B-d) sebaceous gland cells. 
Table I. Differentiation of bone marrow cells into various cell types in skin.

\begin{tabular}{|c|c|c|c|c|c|}
\hline & \multicolumn{3}{|c|}{ Incidence of differentiation events } & \multicolumn{2}{|c|}{ No. of GFP-positive cells } \\
\hline & Whole BM & $\mathrm{MNC}$ & Pellet & $\mathrm{MNC} \%$ & Pellet \% \\
\hline No. of experiments & 7 & 12 & 8 & & \\
\hline $\begin{array}{l}\text { No. of GFP }(+) \text { cells counted (total } \\
\text { no. of cells counted) }\end{array}$ & & & & $100(2,455)$ & $100(1,579)$ \\
\hline Epidermal keratinocytes & $2 / 7$ & $1 / 12$ & $2 / 8$ & 0.3 & 0.5 \\
\hline Hair follicle cells & $4 / 7$ & $2 / 12$ & $8 / 8$ & 4.9 & $23.1^{\mathrm{a}}$ \\
\hline Sebaceous gland cells & $3 / 7$ & $3 / 12$ & $7 / 8$ & 3.3 & $8.3^{\mathrm{b}}$ \\
\hline Dendritic gland cells & $7 / 7$ & $11 / 12$ & $8 / 8$ & 4.3 & 4.1 \\
\hline Endothelial cells & $4 / 7$ & $12 / 12$ & $3 / 8$ & 2.6 & $0.9^{c}$ \\
\hline Muscle cells & - & $2 / 12$ & $3 / 8$ & 0.3 & 0.6 \\
\hline Adipocytes & - & $2 / 12$ & $0 / 8$ & 0.6 & 0.0 \\
\hline Spindle cells & $7 / 7$ & $12 / 12$ & $8 / 8$ & 58.4 & 52.7 \\
\hline Round cells & $7 / 7$ & $12 / 12$ & $8 / 8$ & 25.9 & 9.8 \\
\hline
\end{tabular}

${ }^{\mathrm{a}} \mathrm{MNC}<$ pellet $\mathrm{p}<0.01 .{ }^{\mathrm{b}} \mathrm{MNC}<$ pellet $\mathrm{p}<0.05 .{ }^{\mathrm{c}} \mathrm{MNC}>$ pellet $\mathrm{p}<0.05$ (Mann-Whitney $\mathrm{U}$ test).

Table II. Percentage of cells positive for expression of cell surface markers in MNC and pellet fractions.

\begin{tabular}{lrrc}
\hline & \multicolumn{1}{c}{ MNC } & \multicolumn{1}{c}{ Pellet } & No. of experiments \\
\hline CD45 & $85.7 \pm 2.3$ & $35.5 \pm 4.4$ & $4^{\mathrm{a}}$ \\
CD90 & $4.5 \pm 1.8$ & $2.6 \pm 0.2$ & 4 \\
$\gamma \delta$ TCR & $12.0 \pm 1.9$ & $7.4 \pm 1.4$ & $3^{\mathrm{b}}$ \\
CD34 & $1.2 \pm 1.3$ & $1.5 \pm 0.7$ & 4 \\
CD29 & $95.2 \pm 2.7$ & $94.0 \pm 0.7$ & 4 \\
CD49f & $13.7 \pm 2.3$ & $9.0 \pm 2.2$ & $4^{\mathrm{b}}$ \\
CD200 & $28.4 \pm 0.4$ & $9.3 \pm 0.5$ & $3^{\mathrm{a}}$ \\
CD117 & $14.0 \pm 2.5$ & $4.9 \pm 1.3$ & $9^{\mathrm{a}}$
\end{tabular}

${ }^{\mathrm{a}} \mathrm{MNC}>$ pellet $\mathrm{p}<0.001 .{ }^{\mathrm{b}} \mathrm{MNC}>$ pellet $\mathrm{p}<0.05$ (ANOVA method).

the cells, immunohistochemistry, and specific staining in a manner similar to that in our previous study (23). Epidermal keratinocytes and hair follicle cells were positive for cytokeratin expression (Fig. 3A1-A3) in addition to their specific location and morphology (Fig. 4B-b). Sebaceous gland cells were found in association with hair follicles and were positive for Oil Red O staining (Fig. 3B1-B3). Dendritic cells were found in the epidermis with a characteristic morphology (Fig. 4B-c). Endothelial cells lined the inner surfaces of cylindrical structures (Fig. 4B-a) and were positive for expression of von Willebrand factor (Fig. 3C1-C2). Muscle cells and adipocytes were identified by their morphology and location in tissue. The remaining unspecified cells were classified into spindle and round cells according to their morphology.

Differential contribution of MNC and pellet cell fractions to the reconstitution of skin. Transplantation of the pellet cells in a mixture with embryonic skin cells resulted in a substantial contribution of GFP-positive cells to the formation of hair follicles, while cells from the MNC fraction rarely comprised hair follicles (Fig. 4A, Table I). GFP-positive hair follicle cells were detected in all of the 8 experiments using pellet cells, while GFP-positive cells were observed only in 2 of the 12 transplantation experiments using MNC cells. Cell counting revealed that $4.9 \%$ and $23.1 \%$ of GFP-positive cells were hair follicle cells after transplantation of MNC and pellet cells, respectively (Table I). The difference is statistically significant $(\mathrm{p}<0.01)$. Similarly, the pellet cells differentiated more preferentially into sebaceous gland cells than did the MNC. In contrast, endothelial cells were derived more frequently from $\mathrm{MNC}$ than from pellet cells.

Expression of marker proteins in the cells recovered in MNC and pellet fractions. To gain insight into possible differences in cell populations recovered in MNC and pellet fractions, we examined the expression of representative marker proteins by FACS analysis (Table II). The rates of cells that are positive in the expression of CD45, CD117 (c-kit), and CD200 were significantly lower in the pellet fraction than those in the MNC fraction. The difference in expression rates of CD49f (integrin $\alpha 6$ ) and $\gamma \delta$ TCR was marginal and no difference was noted in the expression rates of CD90 (Thy-1), CD34 and CD29 (integrin 31 ) between the two fractions. Substantial expression of CD45 is known to be observed in virtually all committed hematopoietic cells $(25,26)$. When the cells were analyzed after double immunolabeling, positive cells in the expression of CD117 or CD200 were found solely in the CD45-positive populations (Fig. 5). Furthermore, the positive cell rate in the expression of CD117 or CD200 among CD45positive populations was similar between MNC and pellet fractions. These results indicate that the pellet fraction contains more abundant cells that are not committed to hematopoietic cell lineages. 

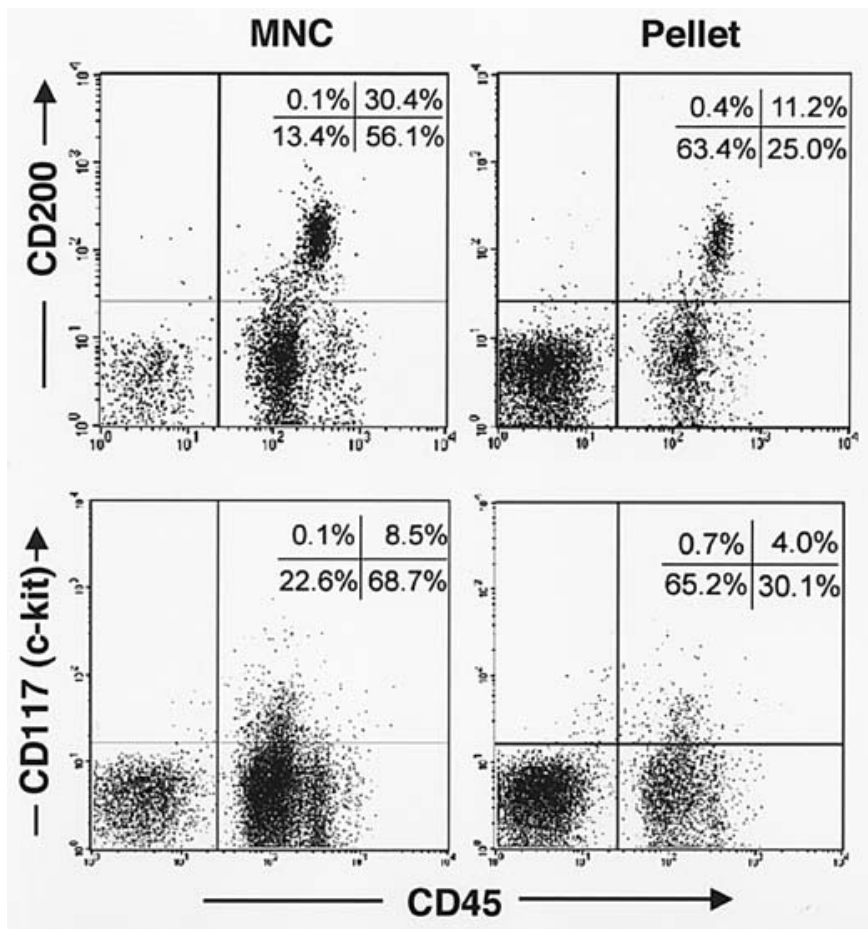

Figure 5. Fluorescent-activated cell sorter analysis of cells recovered in the MNC and pellet fractions after density gradient fractionation. The antibodies against CD45 were conjugated with fluorescein isothiocyanate (green; detected by FL1 covering 515-545 nm) and the antibodies against CD117 (c-kit) and CD200 were conjugated with phycoerythrin (red; detected by FL2 covering 653-669 nm).

\section{Discussion}

In the present study, we showed that a substantial amount of nucleated cells ( $\sim 30 \%$ of whole bone marrow nucleated cells) is contained in the pellet fraction prepared by conventional density gradient fractionation methods, and that the cells exhibit a different differentiation preference into skin cells to that of cells in the MNC fraction. This simple observation is of great significance because the pellet fraction is usually discarded after density gradient centrifugation. To our knowledge, there are no reported studies in which the pellet cells of bone marrow were analyzed in terms of differentiation potential.

Under the present conditions, $31 \%$ and $62 \%$ of bone marrow nucleated cells were recovered in the pellet and MNC fractions, respectively. Cells in the two fractions showed different distribution profiles in dot plotting for forward and side scattering (Fig. 2B and C) and different expression rates of some cell-type specific markers (Table II, Fig. 5). The MNC fraction was eminently composed of committed hematopoietic cells as indicated by the high positivity (86\%) in the expression of CD45. The CD45-positive cells might well explain the preferential differentiation of cells in the MNC into endothelial cells since endothelial cells and hematopoietic cells arise from a common progenitor $(27,28)$. CD45 was expressed in a far less population of cells (36\%) in the pellet fraction. CD29 (integrin 31 ) was detected in $~ 95 \%$ of cells similarly in both fractions, though it is considered as a marker for epidermal stem cells and bone marrow mesenchymal stem cells (29-31).
In GFP-transgenic mice, the reporter gene EGFP was driven by the CAG promoter, which was composed of the cytomegalovirus enhancer, a fragment of the chicken $\beta$-actin promoter and rabbit $\beta$-globin exons (32). This enabled ubiquitous expression of GFP among different tissues (33). There have been several studies, however, showing that some cells are negative in GFP expression and that there is a large difference in the expression levels in different cells in GFPtransgenic mice (34). GFP-negative/weak cells with lower side scattering accounted for $\sim 40 \%$ of the pellet nucleated cells but only $\sim 10 \%$ of the MNCs. These fractionation profiles in dot blotting after FACS analysis remain essentially similar regardless of the different agent used for density gradient centrifugation, i.e. Ficoll, Percoll or Histopaque 1077. The differences in forward/side scattering, GFP expression, and immunophenotypes clearly demonstrate that the population of cells differs between both fractions.

We previously demonstrated that adult mouse bone marrow cells could participate in skin reconstitution (23). Thereafter, many teams have provided compelling evidence indicating that bone marrow-derived cells can be converted into skin cells $(31,35-37)$. These studies demonstrated that not only whole bone marrow cells but also purified hematopoietic stem cells (6) and mesenchymal stem cells (31) can differentiate into skin cells. Furthermore, a pluripotent 'marrow-isolated adult multilineage inducible cells' was recently isolated from adult human bone marrow, which could be propagated extensively and induced to differentiate into cell lineages of all three germ layers (38). Intriguingly, the cells could be isolated only when using unfractionated bone marrow cells but not when the bone marrow cells were subjected to density gradient centrifugation. These results corroborate the indication derived from the present study that density gradient fractionation results in significant loss of specific stem/progenitor cells into the usually discarded pellet fraction.

\section{Acknowledgements}

We thank Miss Aya Niida for her technical assistance. This work was supported by Grants-in-Aid from the Ministry of Education, Science and Culture of Japan (14370260 and 17014065 to N.H.) and the Cosmetology Research Promotion Fund (J-03-20 to N.H.).

\section{References}

1. Reyes M, Lund T, Lenvik T, Aguiar D, Koodie L and Verfaillie CM: Purification and ex vivo expansion of postnatal human marrow mesodermal progenitor cells. Blood 98: 2615-2625, 2001.

2. Quesenberry PJ, Dooner G, Colvin G and Abedi M: Stem cell biology and the plasticity polemic. Exp Hematol 33: 389-394, 2005.

3. Orlic D, Kajstura J, Chimenti S, Jakoniuk I, Anderson SM, Li B, Pickel J, McKay R, Nadal-Ginard B, Bodine DM, Leri A and Anversa P: Bone marrow cells regenerate infarcted myocardium. Nature 410: 701-705, 2001.

4. Brazelton TR, Rossi FM, Keshet GI and Blau HM: From marrow to brain: expression of neuronal phenotypes in adult mice. Science 290: 1775-1779, 2000.

5. Mezey E, Chandross KJ, Harta G, Maki RA and McKercher SR: Turning blood into brain: cells bearing neuronal antigens generated in vivo from bone marrow. Science 290: 1779-1782, 2000 . 
6. Krause DS, Theise ND, Collector MI, Henegariu O, Hwang S, Gardner R, Neutzel S and Sharkis SJ: Multi-organ, multilineage engraftment by a single bone marrow-derived stem cell Cell 105: 369-377, 2001

7. Graf T: Differentiation plasticity of hematopoietic cells. Blood 99: 3089-3101, 2002.

8. Petersen BE, Bowen WC, Patrene KD, Mars WM, Sullivan AK, Murase N, Boggs SS, Greenberger JS and Goff JP: Bone marrow as a potential source of hepatic oval cells. Science 284: 1168-1170, 1999.

9. Avital I, Inderbitzin D, Aoki T, Tyan DB, Cohen AH, Ferraresso C, Rozga J, Arnaout WS and Demetriou AA: Isolation, characterization, and transplantation of bone marrowderived hepatocyte stem cells. Biochem Biophys Res Commun 288: 156-164, 2001.

10. Lagasse E, Connors H, Al-Dhalimy M, Reitsma M, Dohse M, Osborne L, Wang X, Finegold M, Weissman IL and Grompe M: Purified hematopoietic stem cells can differentiate into hepatocytes in vivo. Nat Med 6: 1229-1234, 2000.

11. Pittenger MF, MacKay AM, Beck SC, Jaiswal RK, Douglas R, Mosca JD, Moorman MA, Simonetti DW, Craig S and Marshak DR: Multilineage potential of adult human mesenchymal stem cells. Science 284: 143-147, 1999.

12. Woodbury D, Schwarz EJ, Prockop DJ and Black IB: Adult rat and human bone marrow stromal cells differentiate into neurons. J Neurosci Res 61: 364-370, 2000.

13. Jiang Y, Jahagirdar BN, Reinhardt RL, Schwartz RE, Keene CD, Ortiz-Gonzalez XR, Reyes M, Lenvik T, Lund T, Blackstad M, Du J, Aldrich S, Lisberg A, Low WC, Largaespada DA and Verfaillie CM: Pluripotency of mesenchymal stem cells derived from adult marrow. Nature 418: 41-49, 2002.

14. Schwartz RE, Reyes M, Koodie L, Jiang Y, Blackstad M, Lund T, Lenvik T, Johnson S, Hu WS and Verfaillie CM: Multipotent adult progenitor cells from bone marrow differentiate into functional hepatocyte-like cells. J Clin Invest 109: 1291-1302, 2002.

15. Goodell MA, Brose K, Paradis G, Conner AS and Mulligan RC: Isolation and functional properties of murine hematopoietic stem cells that are replicating in vivo. J Exp Med 183: 1797-1806, 1996.

16. Pearce DJ, Ridler CM, Simpson C and Bonnet D: Multiparameter analysis of murine bone marrow side population cells. Blood 103: 2541-2546, 2004.

17. Olmsted-Davis EA, Gugala Z, Camargo F, Gannon FH, Jackson K, Kienstra KA, Shine HD, Lindsey RW, Hirschi KK, Goodell MA, Brenner MK and Davis AR: Primitive adult hematopoietic stem cells can function as osteoblast precursors. Proc Natl Acad Sci USA 100: 15877-15882, 2003.

18. Wulf GG, Luo KL, Jackson KA, Brenner MK and Goodell MA: Cells of the hepatic side population contribute to liver regeneration and can be replenished with bone marrow stem cells. Haematologica 88: 368-378, 2003.

19. Korbling $M$ and Estrov Z: Adult stem cells for tissue repair - a new therapeutic concept? N Engl J Med 349: 570-582, 2003.

20. Miller RG and Phillips RA: Separation of cells by velocity sedimentation. J Cell Physiol 73: 191-201, 1969.

21. Iacone A, Quaglietta AM, D'Antonio D, Accorsi P, Dragani A, Angrilli F, Berardi A, Angelini A, Di Bartolomeo P, Di Bartolomeo G, et al: Density gradient separation of hematopoietic stem cells in autologous bone marrow transplantation. Haematologica 76 (suppl 1): 18-21, 1991.
22. Barker JE and McFarland EC: A method to enrich mouse hematopoietic stem cells. Blood 62: 827-831, 1983.

23. Kataoka K, Medina RJ, Kageyama T, Miyazaki M, Yoshino T, Makino T and Huh NH: Participation of adult mouse bone marrow cells in reconstitution of skin. Am J Pathol 163: 1227-1231, 2003.

24. Fusenig NE, Breitkreutz D, Dzarlieva RT, Boukamp P, Bohnert A and Tilgen W: Growth and differentiation characteristics of transformed keratinocytes from mouse and human skin in vitro and in vivo. J Invest Dermatol 81: 168S-175S, 1983.

25. Trowbridge IS, Ostergaard HL and Johnson P: CD45: a leukocytespecific member of the protein tyrosine phosphatase family. Biochim Biophys Acta 1095: 46-56, 1991.

26. Dahlke MH, Lauth OS, Jager MD, Roeseler T, Timrott K, Jackobs $\mathrm{S}$, Neipp $\mathrm{M}$, Wonigeit $\mathrm{K}$ and Schlitt $\mathrm{HJ}$ : In vivo depletion of hematopoietic stem cells in the rat by an anti-CD45 (RT7) antibody. Blood 99: 3566-3572, 2002.

27. Bailey AS and Fleming WH: Converging roads: evidence for an adult hemangioblast. Exp Hematol 31: 987-993, 2003.

28. Choi K, Kennedy M, Kazarov A, Papadimitriou JC and Keller G: A common precursor for hematopoietic and endothelial cells. Development 125: 725-732, 1998.

29. Jones PH and Watt FM: Separation of human epidermal stem cells from transit amplifying cells on the basis of differences in integrin function and expression. Cell 73: 713-724, 1993.

30. Kaur P and Li A: Adhesive properties of human basal epidermal cells: an analysis of keratinocyte stem cells, transit amplifying cells, and postmitotic differentiating cells. J Invest Dermatol 114: 413-420, 2000

31. Deng W, Han Q, Liao L, Li C, Ge W, Zhao Z, You S, Deng H, Murad $\mathrm{F}$ and Zhao RC: Engrafted bone marrow-derived flk-(1+) mesenchymal stem cells regenerate skin tissue. Tissue Eng 11: $110-119,2005$.

32. Niwa H, Yamamura K and Miyazaki J: Efficient selection for high-expression transfectants with a novel eukaryotic vector. Gene 108: 193-199, 1991.

33. Ikawa M, Yamada S, Nakanishi T and Okabe M: 'Green mice' and their potential usage in biological research. FEBS Lett 430: 83-87, 1998.

34. Fujikawa T, Hirose T, Fujii H, Oe S, Yasuchika K, Azuma H and Yamaoka Y: Purification of adult hepatic progenitor cells using green fluorescent protein (GFP)-transgenic mice and fluorescence-activated cell sorting. J Hepatol 39: 162-170, 2003.

35. Badiavas EV, Abedi M, Butmarc J, Falanga V and Quesenberry P: Participation of bone marrow derived cells in cutaneous wound healing. J Cell Physiol 196: 245-250, 2003.

36. Borue X, Lee S, Grove J, Herzog EL, Harris R, Diflo T, Glusac E, Hyman K, Theise ND and Krause DS: Bone marrow-derived cells contribute to epithelial engraftment during wound healing. Am J Pathol 165: 1767-1772, 2004.

37. Brittan M, Braun KM, Reynolds LE, Conti FJ, Reynolds AR, Poulsom R, Alison MR, Wright NA and Hodivala-Dilke KM: Bone marrow cells engraft within the epidermis and proliferate in vivo with no evidence of cell fusion. J Pathol 205: 1-13, 2005.

38. D'Ippolito G, Diabira S, Howard GA, Menei P, Roos BA and Schiller PC: Marrow-isolated adult multilineage inducible (MIAMI) cells, a unique population of postnatal young and old human cells with extensive expansion and differentiation potential. J Cell Sci 117: 2971-2981, 2004. 